\title{
ENTRE CONQUISTAS E LUTAS: UMA ANÁLISE DA SAÚDE MENTAL DA POPULAÇÃO LGBT+ BRASILEIRA
}

\author{
Lisía Maria Monteiro Ferreira (UNIFSA) ${ }^{1}$ \\ Antônia Thacyara Dias de Brito (CEUMA) ${ }^{2}$ \\ Brenna Galtierrez Fortes Pessoa (UNIFSA) ${ }^{3}$ \\ Maria Karuline de Sousa Lima (UNIFSA) ${ }^{4}$ \\ Francisca Kananda Lustosa dos Santos (FAR) ${ }^{5}$ \\ Nathália Gomes Duarte(UNIFSA) ${ }^{6}$ \\ João Caio Silva Castro Ferreira (FAESPI) ${ }^{7}$
}

\section{RESUMO}

A problematização deste estudo consiste-se em refletir sobre aspectos em torno da saúde mental da população LGBT+. Com o objetivo de analisar a saúde mental dessa população, partindo-se do pressuposto de como esse viés da saúde mental está sendo visto, ou vivenciado pelos os mesmos. E, tal problemática é urgente, uma vez que vivemos em uma sociedade binária, que por sua vez priva pessoas de viveram suas identidades de gênero e orientações concernentes a sua sexualidade. O método foi uma revisão integrativa, realizada entre julho a agosto de 2019. Os estudos analisados são de pesquisas de campos de diferentes modalidades e regiões do Brasil, os participantes das pesquisas são travestis, jovens homoafetivos (mulheres e homens), grupos ativistas, entre outros integrantes da comunidade LGBT+. Através das análises foi possível perceber que os sofrimentos psíquicos da população em questão estão intrinsecamente relacionados à violência e a não aceitação deste público em alguns grupos sociais. Contudo, o estudo mostra a necessidade de construir novos horizontes que busquem dialogar com mais intensidade e maturidade acerca do debate sobre sexualidade em diversos contextos, seja eles na sociedade, escola e família.

\section{Palavras-Chave: Lgbt. Saúde Mental. Violência}

Trabalho apresentado no Congresso Brasileiro Ciência e Sociedade (CBCS 2019), promovido pelo Centro Universitário Santo Agostinho, de 03 a 05 de outubro de 2019, em Teresina-PI.

${ }^{1}$ Graduanda em Psicologia. Integrante do Projeto de Extensão "Um Olhar sobre a diversidade: discutindo corpo, sexo e gênero "- Centro Universitário Santo Agostinho (UNIFSA). E-mail: lisiamonteiro2015@outlook.com

${ }^{2}$ Psicóloga graduada pelo Centro Universitário do Maranhão. Membro do grupo de Estudo e Pesquisa em Psicologia Social, atuando na linha de pesquisa Políticas Públicas para Crianças e Adolescentes. Pós-graduanda em Saúde Mental e Políticas Públicas. Integrante da LAPSMA (Liga Acadêmica de Psicologia Social do Maranhão). E-mail: thacyaradias@gmail.com

${ }^{3}$ Bacharel em Serviço Social pelo Centro Universitário Santo Agostinho (UNIFSA). Integrante do Projeto de Extensão "Um Olhar sobre a Diversidade: discutindo corpo, sexo e gênero"- Centro Universitário Santo Agostinho (UNIFSA). Pósgraduanda em Docência no Ensino Superior (UNIFSA).E-mail: brennagaltierrez@hotmail.com

${ }^{4}$ Graduanda em Psicologia. Integrante do Projeto de Extensão "Um Olhar sobre a diversidade" - Centro Universitário Santo Agostinho (UNIFSA). E-mail: mariakarulinelima@outlook.com

${ }^{5}$ Bacharel em Serviço Social pelo Centro Universitário Santo Agostinho (UNIFSA). Pós- Graduanda em Políticas Públicas, Gestão e Serviços Sociais pela Faculdade Ademar Rosado- FAR. E-mail: knanda.13@hotmail.com

${ }^{6}$ Graduanda em Psicologia. Integrante do Projeto de Extensão “Um Olhar sobre a diversidade: discutindo corpo, sexo e gênero"- Centro Universitário Santo Agostinho (UNIFSA. E-mail: natgomesd@gmail.com

${ }^{7}$ Orientador do trabalho. Enfermeiro pela Universidade Federal do Piauí e Especialização em andamento em Saúde Mental e Políticas Públicas pela Faculdade Evangélica do Piauí - FAESPI. E-mail: joaovscaiovscastro@outlook.com 
INTRODUÇÃO

O debate sobre gênero e suas ramificações são terminologias que com o tempo passou a ser associada às questões de discriminações, violências e preconceitos, inclusive, influenciando nos relacionamentos interpessoais das pessoas, isso se deve a uma lógica patriarcal de aspectos machistas que assolam a sociedade durante várias décadas, esta é responsável por normatizar e qualificar os papéis sociais de cada sexo, ao ponto de ser naturalizada, no entanto há pessoas que não conseguem se encaixam em tais padrões, e com isso, são excluídos dos meios em que vivem, onde qualquer discussão acerca do assunto, no sentido de confrontar é estigmatizada (LINS, MACHADO, ESCOURA, 2016).

$\mathrm{Na}$ atualidade, muito tem-se discutido em todas as instâncias sociais sobre a diversidade de gênero, de orientação sexual e sexualidade humana. Uma temática que vem ganhando notoriedade, visto que com os avanços dos estudos feministas desde os anos 70 , vieram a rejeitar os determinantes biológicos sobre esta temática, ao passo de contrapor ideias hetenormativas e lógicas binárias (LOURO, 2003).

Apesar de tais avanços, a comunidade Lésbicas, Gays, Bissexuais e Travestis (LGBT+) ainda sofrem com o preconceito e discriminação diante de sua forma e expressão da sexualidade. Tendo em vista os altos índices de homicídios e suicídios envolvendo essa população, como traz o Relatório do Grupo Gay da Bahia (2018). Em que os gays são os que mais tiram sua vida (60\%), em seguida vem às lésbicas com o percentual de $31 \%$, trans $6 \%$, bissexuais com $3 \%$. Em casos de homicídios, o relatório traz as lésbicas com $12 \%$ dos casos, um dado que demonstra grande diferença ao outro (suicídio). No caso do seguimento trans o número de homicídios ultrapassa o de suicídio chegando a $39 \%$.

Uma das principais dificuldades relacionadas ao grupo em estudo e a constante não aceitação social que essa população enfrenta em seu cotidiano, visto que se destacam como o seguimento populacional que mais se suicida no Brasil. De acordo com o relatório do Grupo Gay da Bahia (2018) as pessoas LGBT+ são 6 vezes mais propensos de comentar suicídio.

Outro ponto questionável que se debruça sobre a saúde emocional dos mesmos, são as situações de vulnerabilidades cotidianas aos quais estas pessoas estão constantemente expostas, como por exemplo: a rejeição familiar, quando a mesma sabe sobre a descoberta a identidade de 
gênero e orientação do filho (a), a rejeição social e o discurso de ódio, tais situações podem expor as pessoas LGBT+ há sofrimentos psíquicos e vulneráveis a ideação suicida, quadros depressivos entre outros (CAMPOS; ALVES, 2015).

Diante do que se expõe, é necessário refletir sobre os aspectos da saúde mental da população LGBT+ visto que segundo a OMS (Organização Mundial da Saúde), a saúde se caracteriza com um estado de bem-estar físico, mental, espiritual e social, não apenas ausência de enfermidades. Sendo um direito de cidadania a qualquer pessoa sem distinção. No que tange o viés da saúde mental, constitui-se de um pilar importante na vida e na saúde global do ser humano, pois ela possibilita o indivíduo a se relacionar entre pessoas e grupos, visto que a saúde mental engloba as capacidades cognitivas resultando um bom funcionamento interno e externo e um desequilibro pode trazer sérios danos (DE SOUZA; BAPTISTA, 2017).

Com isso, o presente estudo tem como objetivo analisar a saúde mental da população LGBT+, partindo-se do pressuposto de como esse viés da saúde mental está sendo visto, ou vivenciado pelos mesmos. Na alternativa de listar as interfaces dos transtornos mais evidentes. Tal problemática é urgente, uma vez que vivemos em uma sociedade binária, que por sua vez priva pessoas de viveram suas identidades de gênero e orientações concernentes a sua sexualidade.

\section{METODOLOGIA}

O método de pesquisa aplicado neste estudo foi a revisão integrativa da literatura, ela foi realizada entre julho a agosto de 2019 , este formato foi escolhido por responder ao objetivo de estudo e permitir a reunião de conhecimentos científicos acerca do que já foi publicado sobre o tema em investigação.(KAKUSHI; ÉVORA, 2016)

Esse método de pesquisa é reconhecido por revelar uma vasta abordagem metodológica à cerca de revisões, proporcionando a inclusão de vários estudos com diferentes propostas de pesquisa que auxiliaram na assimilação do fenômeno debatido, além de se reunir outros dados para dar complexidade ao estudo (KAKUSHI; ÉVORA, 2016; SOUZA; SILVA, 2010).

Ao se construir este estudo foi respeitado às seguintes etapas: a princípio identificação do tema a ser desbravado; buscou-se nas bases científicas a viabilidade para que o estudo possa ser construído, tendo-se como base a quantidade de artigos científicos já publicados sobre o assunto; analisaram-se os dados identificados de acordo com o método apresentado, além de analisar a amostra de cada estudo e os seus resultados. Para conduzir este trabalho, construiu-se o seguinte 


\section{CONGQEESSOCIENCIAESOCIEDADE

questionamento direcionador: Como está à saúde mental da população LGBT+ segundo as publicações científicas publicadas?

Para a escolha dos artigos foram aplicadas duas bases de dados: Science Eletronic Online SciELO, Biblioteca Virtual em Saúde (BVS). Para localizar os materiais analisados, foi feito o cruzamento entre os respectivos descritores: Saúde mental and LGBT,saúde mental and orientação sexual, saúde mental and identidade de gênero, saúde mental and lésbicas, saúde mental and gays, saúde mental and bissexuais, saúde mental and transsexuais, saúde mental and travestis. O operador lógico "and" foi aplicado para somar os descritores referidos anteriormente (NESELLO, et al., 2014).

Os critérios de inclusão aplicados para a seleção dos artigos científicos foram: Artigos científicos publicados entre 2015-2019; que tenham sido publicados no idioma português; que estejam disponíveis na íntegra. Todavia, a definição amostral aconteceu após certificação de que estes artigos se encaixavam nestes critérios e se eles abordavam a temática explorada pela pesquisa.

Para os critérios de exclusão foi estabelecido que outras revisões de literatura, assim como, teses, dissertações e trabalhos de conclusão de curso, artigos duplicados e fora do recorte temporal pré-definido, não serão aplicados neste estudo. Após a seleção dos artigos, seguiu-se para a análise dos mesmos, onde foi destacado o local que a pesquisa foi concebida, o tipo de pesquisa, o perfil amostral, a quantidade de sujeitos que compuseram a pesquisa, os achados concernentes à saúde mental destas pessoas e os tipos de violência registrada.

\section{RESULTADOS E DISCUSSÃO}

O estudo de revisão integrativa de literatura foi construído através de uma amostra de 7 estudos com base na temática da Saúde Mental a população LGBT+, segundo os critérios de inclusão exclusão já mencionados.

Os estudos analisados são de pesquisas de campos de diferentes modalidades e regiões do Brasil (Tabela 1), os participantes das pesquisas são travestis, jovens homoafetivos (mulheres e homens), grupos ativistas, entre outros integrantes da comunidade LGBT+.

Através das análises foi possível perceber que que o sofrimentos psíquico da população em questão, está intrinsecamente relacionado à violência e a não aceitação deste público em alguns grupos sociais, como a escola, família e a própria sociedade 


\section{CONGGESSOCIENCIAESOCIEDADE \\ Inovação, Diversidaalle e Sustentabilititalle}

Análise dos artigos coletados para a construção do estudo

\begin{tabular}{|c|c|c|c|c|c|c|}
\hline Título & Autor & Local & Ano & Tipo de pesquisa & Participantes & $\begin{array}{c}\text { Vulnerabilidades } \\
\text { psíquicas }\end{array}$ \\
\hline $\begin{array}{c}\text { Violência e } \\
\text { sofrimento social } \\
\text { no itinerário } \\
\text { de travestis de } \\
\text { Santa Maria, Rio } \\
\text { Grande } \\
\text { do Sul, Brasil }\end{array}$ & $\begin{array}{c}\text { SOUZA } \\
\text {,M.H.T } \\
\cdot \\
\text { et al }\end{array}$ & $\begin{array}{l}\text { Santa } \\
\text { Maria, } \\
\text { Rio } \\
\text { Grande } \\
\text { do Sul }\end{array}$ & 2015 & Etnográfica & Travestis & $\begin{array}{c}\text { Depressão, } \\
\text { tentativa de } \\
\text { suicídio, ferimentos } \\
\text { e agravos dos mais } \\
\text { diversos. }\end{array}$ \\
\hline $\begin{array}{l}\text { Descobrir, aceitar e } \\
\text { assumir a } \\
\text { homoafetividade: } \\
\text { situações } \\
\text { de vulnerabilidade } \\
\text { entre jovens }\end{array}$ & $\begin{array}{l}\text { ZANAT } \\
\text { TA, } \\
\text { E.A.;et } \\
\text { al }\end{array}$ & 2018 & $\begin{array}{l}\text { Chapecó- } \\
\text { Santa } \\
\text { Catarina }\end{array}$ & $\begin{array}{c}\text { Pesquisa descritiva } \\
\text { e qualitativa }\end{array}$ & $\begin{array}{c}25 \text { jovens } \\
\text { homoafetivos, } \\
\text { sendo } 13 \\
\text { mulheres e } 12 \\
\text { homens. }\end{array}$ & $\begin{array}{c}\text { Medo, insegurança, } \\
\text { não aceitação e } \\
\text { violência de diversas } \\
\text { formas }\end{array}$ \\
\hline $\begin{array}{l}\text { Álcool, drogas e } \\
\text { violência: } \\
\text { implicacões para a } \\
\text { saúde de minorias } \\
\text { sexuais }\end{array}$ & $\begin{array}{l}\text { PAREN } \\
\text { TE, } \\
\text { J.S.; et } \\
\text { al }\end{array}$ & 2015 & $\begin{array}{l}\text { Juazeiro } \\
\text { do Norte } \\
\text { e Crato, } \\
\text { Ceará, } \\
\text { Brasil }\end{array}$ & $\begin{array}{c}\text { Pesquisa } \\
\text { transversal e } \\
\text { quantitativa }\end{array}$ & $\begin{array}{c}316 \\
\text { integrantes } \\
\text { LGBT }\end{array}$ & $\begin{array}{c}\text { A violência } \\
\text { psicológica/verbal } \\
(78,8 \%) \text { juntamente } \\
\text { com o alto consumo } \\
\text { de álcool }(70,9 \%)\end{array}$ \\
\hline $\begin{array}{l}\text { “Tem que Nascer já } \\
\text { com Aquele Dom”: } \\
\text { Vivências de uma } \\
\text { Jovem Travesti }\end{array}$ & $\begin{array}{l}\text { AZEVE } \\
\text { DO } \\
\text { R.N.;et } \\
\text { al }\end{array}$ & 2015 & São Paulo & $\begin{array}{l}\text { Estudo de caso de } \\
\text { corte transversal, } \\
\text { fundamentado na } \\
\text { abordagem } \\
\text { qualitativa e no } \\
\text { método } \\
\text { fenomenológico }\end{array}$ & $\begin{array}{c}\text { Uma pessoa } \\
\text { travesti }\end{array}$ & $\begin{array}{l}\text { A ansiedade e a } \\
\text { angústia } \\
\text { relacionada ao } \\
\text { convívio paternal }\end{array}$ \\
\hline "Fazer emergir o & VIEIRA, & 2019 & Natal/ Rio & Estudo etnográfico & $\begin{array}{l}\text { Um grupo } \\
\begin{array}{r}\text { DOI: } 10.176 \\
\mid \mathbf{5}\end{array}\end{array}$ & $\begin{array}{l}\text { ISBN: } 978-65-80968-11-4 \\
\text { DOI: } 10.17648 / \text { cbcs-2019-110620 }\end{array}$ \\
\hline
\end{tabular}




\section{conghESSO CIENCIAESOCIEDADE \\ $\rightarrow$ Inovação, Diversidaaile e Sustentahililiadle}

\begin{tabular}{|c|c|c|c|c|c|c|}
\hline $\begin{array}{l}\text { masculino": noções } \\
\text { de } \\
\text { "terapia" epatologiz } \\
\text { ação na } \\
\text { hormonização de } \\
\text { homens trans }\end{array}$ & $\begin{array}{l}\text { C.;POR } \\
\text { TO } \\
\text { R.M }\end{array}$ & & $\begin{array}{l}\text { Grande } \\
\text { do Norte }\end{array}$ & & $\begin{array}{c}\text { ativista de } \\
\text { homens trans } \\
\text { na cidade de } \\
\text { Natal/RN }\end{array}$ & $\begin{array}{l}\text { disforia de gênero, } \\
\text { depressão, consumo } \\
\text { inadequado de } \\
\text { hormônios }\end{array}$ \\
\hline $\begin{array}{l}\text { Relatos de jovens } \\
\text { homoafetivossobre } \\
\text { sua trajetória e } \\
\text { implicações para a } \\
\text { saúde mental }\end{array}$ & $\begin{array}{l}\text { GUIMA } \\
\text { RÃES } \\
\text { A.N.; } \\
\text { et al }\end{array}$ & 2019 & $\begin{array}{c}\text { Santa } \\
\text { Catarina }\end{array}$ & $\begin{array}{l}\text { Pesquisa } \\
\text { qualitativa, } \\
\text { descritiva }\end{array}$ & $\begin{array}{c}19 \text { jovens } \\
\text { homoafetivos } \\
12 \text { são } \\
\text { homens e sete } \\
\text { mulheres, } \\
\text { com idades } \\
\text { variando de } 18 \\
\text { anos a } 23 \text { anos }\end{array}$ & $\begin{array}{l}\text { A relação entre as } \\
\text { dificuldades dos } \\
\text { jovens em relação a } \\
\text { descoberta da } \\
\text { homoafetividade } \\
\text { e o convívio familiar } \\
\text { e grupos sociais } \\
\text { (culturais e } \\
\text { religiosos) }\end{array}$ \\
\hline $\begin{array}{c}\text { Bem-estar } \\
\text { psicológico entre } \\
\text { travestis e } \\
\text { mulheres } \\
\text { transexuais no } \\
\text { Estado de São } \\
\text { Paulo, Brasil }\end{array}$ & $\begin{array}{l}\text { ZUCCH } \\
\text { I, } \\
\text { E.M.;E } \\
\text { T al }\end{array}$ & 2019 & São Paulo & Estudo transversal & $\begin{array}{c}602 \text { travestis e } \\
\text { pessoas } \\
\text { transexuais }\end{array}$ & $\begin{array}{l}\text { Menor bem-estar } \\
\text { psicológico, } \\
\text { insatisfeita com as } \\
\text { relações pessoais, } \\
\text { suporte de amigos } \\
\text { e/ou com } \\
\text { procedimentos } \\
\text { transexualizadores } \\
\text { realizados e ter } \\
\text { sofrido violência } \\
\text { verbal ou sexual }\end{array}$ \\
\hline
\end{tabular}

As pesquisas apresentadas na tabela, fazem um panorama da violência e fatores que levam ao sofrimento psíquico da população LGBT+, interligando a saúde mental dos mesmos. Todavia, para compreender este fenômeno e necessários aprofundar-se nas questões sociais condizentes a este contexto.

A heterossexualidade é uma forma de compreender, especificar e idealizar as relações sociais padrões entre os sexos, desta forma, foi este discurso que originou os rótulos binários, que 


\section{CONGEESSO CIENCIAESOCIEDADE \\ Inovação, Diversidadie e Sustentahilitidade}

são: de pessoas como sendo femininas ou masculinas nas sociedades ocidentais.

Consequentemente, por meio desta dualidade que se emergiu construções biológicas fixas e que não levam em consideração as construções sociais. (HASSOUNEH,GLASS, 2008).

Se tratando da conceituação e construções sociais alguns teóricos contrapõe tais ideias, como a teórica Judith Butler (2003) que defende o gênero como uma construção social de poder e subjetividade, parafraseando em seu livro (Problemas de Gênero: Feminismo e subversão da Identidade) alguns pensamentos que focalizam suas ideias, como "Mulher não nasce mulher, torna-se mulher (Simone de Beauvoir)" e "A manifestação da sexualidade... estabeleceu uma noção de sexo (Michael Foucault)".

A autora Joan Scott (1989, p. 21), também é uma das referências mais utilizadas sobre o assunto, completa esse conceito como: "[...] um elemento constitutivo de relações sociais baseado nas diferenças percebidas entre os sexos, e o gênero é uma forma primeira de significar as relações de poder [...]". Acrescenta, que esse conceito não pode ser entendido separadamente de 4 elementos que se relacionam entre si: o primeiro diz respeito aos símbolos que culturalmente estão disponíveis (ex: Eva e Maria). O segundo são os conceitos normativos que são expressos nas instancias sociais, como a educação, a religião, a política, entre outros. O terceiro remete a uma posição dominante tida como única e o quarto remete a identidade subjetiva.

Mesmo com a noção de que gênero vem que uma construção pessoa, o nosso sistema social dita padrões de forma heteronormativas, cujas ordens dominantes se faz a lógica binária, visto que perpassam regras que restringem na tentativa de enquadrar indivíduos a estereótipos de gênero os levando as situações de desigualdades (LINS, MACHADO, ESCOURA, 2016).

A partir desta situação e que se percebe o quanto a repressão às pessoas LGBT+ são tão intensas, afinal são pessoas que socialmente seguindo a sua identidade de gênero ou orientação sexual, não se encaixam neste modelo sexista.

De acordo com dados de Grupos de Defesa LGBT no Brasil, foi constatado que a cada 23 horas segundo relatório do Grupo Gay da Bahia (GGB) divulgado em 2019. De acordo com a Organização Não Governamental (ONG), foram 126 homicídios, devido à violência contra as pessoas LGBT e infelizmente, somente $17 \%$ dos agressores são localizados (MOTT, MICHELS, PAULINHO, 2017).

Esta realidade expressa o quanto o preconceito e a não aceitação social das pessoas LGBT e tão enraizada, afinal, como foi supracitado, constantemente estas pessoas são violadas por 


\section{CONGQEESSOCIENCIAESOCIEDADE

simplesmente expressarem suas identidades sociais. Fato predominante, principalmente entre as pessoas transexuais e travestis.

Ao se pensar nas dificuldades da inserção social da população trans, principalmente no mercado de trabalho, percebe-se o quanto a não aceitação social dessas pessoas é marcante, ressaltando isso, é a dificuldade de acesso ao mercado de trabalho para essas pessoas, afinal o preconceito e a transfobia; questões burocráticas relacionadas à documentação; uso de ambientes íntimos e públicos como: banheiro e vestiário atuam como barreiras para a não entrada dessas pessoas seja em ambientes privados ou públicos (ALMEIDA, VASCONCELLOS, 2018).

O preconceito e a discriminação contra pessoas LGBT+ são episódios bastante recorrentes em nosso cotidiano, possuindo-se várias formas e modos de serem expressados, além disso, eles tentam delimitar normas e padrões pré-estabelecidos socialmente. Esses fenômenos, quando se apresentam em forma de violência, buscam oprimir um grupo específico ou pessoa em relação a outro tido como diferente. (MENEZES, SILVA, 2017).

A Igbtfobia gera medo, que elimina possibilidades, validando solicitações de controle e disciplina, além de marcar uma pessoa como inimiga. Devido o medo, o corpo-lgbtfóbico, precisa ser achado, contido, exterminado, para a proteção do próprio indivíduo LGBT+, desde que o mesmo esteja dentro dos padrões heteronormativos. Compreende-se que a violência tornou-se de caráter individual e naturalizada, ao ponto que a erradicação sistemática das pessoas que não cumprem com os padrões heteronormativas, segue sendo feita de forma silenciosa e cada vez mais severa (CASSAL, BICALLO, 2011).

As vivências de casos de violência entre as pessoas LGBT+ costumam partir de alguns grupos sociais, como a escola, a família, além da própria sociedade. A escola se faz um ambiente hostilizado a tal grupo, visto que o cotidiano da escola fabrica normas heteronormativas o modo de se sentar, modos de agir, de se posicionar, construindo normas fixas e padronizadas para meninos e meninas (LOURO, 2003).

Nesse ponto, a escola se faz como uma das instâncias que exclui, contrapondo seu papel. Autores como Madureira; Branco (2015), Oliveira; Alberto; Bittencurt (2016), Machado; Pires (2016), Sousa; Silva; Santos (2017) discutem que a escola silencia e vela quando o assunto recai para alunos e alunas que não estão em conformidade com os padrões de orientação e identidade de gênero. 
Louro (2003) colabora que a ausência da fala e o silencio exercido pela escola, faz com que eles não ultrapassem a "norma". A negação aos homossexuais nas vivencia diárias da escola, faz com que alunos gays e alunas lésbicas sejam alvos de preconceitos e discriminações. Fazendo com que eles e elas se sintam como indesejáveis e desviantes das normas.

Em uma pesquisa nas escolas estaduais na cidade de Santa Maria (RS), as professoras entrevistadas relataram que não há uma preocupação formalizada em relação à discussão sobre sexualidade no ambiente escolar, além disso, pode-se notar o quanto as discriminações e brincadeiras de cunho homofóbicas, são desprezadas, o que reforça este ambiente hostil para jovens LGBT+ dentro das escolas (BORGES, et al., 2011)

Sobretudo, além da escola a família também costuma ser um dos contextos mais problemáticos para pessoas LGBT+, quando estas pessoas se assumem para seus familiares, um processo de turbulências e violência fica marcado na vida de algumas das pessoas LGBT+, pois alguns familiares não costumam aceitar tão facilmente a sexualidade de seus entes, a prova disso, algumas pessoas LGBT+, ainda são expulsas de casa e são repreendidas brutalmente por não se encaixarem no padrão heteronormativo (BRAGA, et al.,2017)

A entidade família é um dispositivo criado historicamente para resguardar a sexualidade de seus membros, desta forma, garantindo a repercussão secular de sua futura geração, tal concepção, serve para compreender os comportamentos agressivos quando uma familiar assume sua homossexualidade, pois o mesmo não se enquadra no padrão heteronormativo cultivado pelos seus familiares desde quando o mesmo era criança, o que não implica dizer, que por essa pessoa ser LGBT+, ela não possa ter uma família, mesmo ela não sendo nos moldes tradicionais (TOLEDO, TEIXEIRA FILHO, 2011).

Entre tantos preconceitos e violações de direito, as pessoas LGBT+, se encontram no centro de entidades e instituições que ainda insistem em não compreender e acolher, as diversidades e suas expressões, este estudo evidenciou que nesta zona de conflitos, a saúde mental das pessoas LGBT+ se torna bastante vulnerável a agravos biopsicossociais que estão diretamente relacionadas com o cenário de exclusão que essas pessoas costumam vivenciar.

\section{CONSIDERAÇÕES FINAIS/CONCLUSÕES}


É nítido que as pessoas LGBT+, encontram-se em uma situação de vulnerabilidade biopsicossocial, por não serem aceitas socialmente devido a sua orientação sexual ou identidade de gênero não corresponderem aos padrões heternormativos cobrados em nossa sociedade.

Contudo, precisa-se urgentemente se construir novos horizontes que busquem dialogar com mais intensidade e maturidade, o debate sobre sexualidade em diversos contextos, seja eles na sociedade, escola e família. Além disso, esta pesquisa foi um ponto de partida para que outros(as) pesquisadores(as) se sensibilizem em continuar retratando estes contextos de vulnerabilidade, para que através destas constatações, possa-se ter registros científicos que evidenciem a importância de políticas públicas que atuem nos debates supracitados.

A literatura sobre o assunto deste estudo ainda é escassa, sabe-se que se existe vários outros contextos de exclusão relacionados à população LGBT+, porém poucas pesquisas ainda não alcançaram estes cenários. É fato, que a população LGBT+ é plural, desta forma, ressalvo o quanto é importante entender esta pluralidade e dialogá-la em diferentes espaços.

\section{REFERÊNCIAS}

AZEVEDO, Roberta Noronha; SCORSOLINI-COMIN, Fabio; SPIZZIRRI, Giancarlo. " Tem que nascer já com aquele dom": vivências de uma joven travesti. Revista da Abordagem Gestáltica: PhenomenologicalStudies, v. 21, n. 2, p. 201-212, 2015.

BORGES, Zulmira Newlandset al. Percepção de professoras de ensino médio e fundamental sobre a homofobia na escola em Santa Maria (Rio Grande do Sul/Brasil). Educar em Revista, n. 39, p. 2138, 2011.

BRAGA, lara Falleiroset al. Violência familiar contra adolescentes e jovens gays e lésbicas: um estudo qualitativo. Revista Brasileira de Enfermagem-REBEn, v. 71, p. 1295-1303, 2017.

BUTLER, Judith P. Problemas de gênero: feminismo e subversão da identidade/ Judith Butler; tradução, Renato Aguiar. Rio de Janeiro: Civilização Brasileira, 2003.

CAMPOS, Jéssica Lisboa; ALVES, Jéssica Luana da Silva. A Invisibilidade da Saúde da População Lgbt: Uma Reflexão acerca da Homofobia Presente nos Espaços Institucionais de Saúde. In: Anais da VII Jornada Internacional de Políticas Públicas: Para além da crise global: experiências e antecipações concretas, São Luís 25 a 28 de agosto de 2015. - São Luís: Universidade Federal do Maranhão, Programa de Pós Graduação em Políticas Públicas, 2015.

DE OLIVEIRA, Cleide Ester; ALBERTO, Maria de Fatima Pereira; BITTENCOURT, Nadir de Fátima Borges. Tensões e contradições nos discursos políticos sobre o combate à homofobia no contexto 


\section{GONGQESSOCOENCIA:SOCIEDADE}

da escola brasileira. Revista Latinoamericana de CienciasSociales, Niñez y Juventud, v. 14, n. 2, p. 1479-1492, 2016.

DE SOUZA, Mayra Silva; BAPTISTA, Makilim Nunes. Associações entre suporte familiar e saúde mental. Psicologia Argumento, v. 26, n. 54, p. 207-215, 2017.

GRUPO GAY DA BAHIA - GGB. Mortes Violentas de LGBT+ no Brasil: Relatório 2018. Bahia, 2018.

HASSOUNEH, Dena; GLASS, Nancy.The influence of gender role stereotyping on women's experiences of female same-sex intimate partner violence. ViolenceAgainstWomen, v. 14, n. 3, p. 310-325, 2008.

KAKUSHI, Luciana Emi; ÉVORA, Yolanda Dora Martinez. As redes sociais na educação em enfermagem: revisão integrativa da literatura. Revista Latino-Americana de Enfermagem, v. 24, p. $1-12,2016$.

LINS, Beatriz Accioly; MACHADO, Bernardo Fonseca; ESCOURA, Michele. Diferentes, não desiguais: a questão de gênero na escola. São Paulo: Reviravolta, 2016.

LOURO, Guacira Lopes. Gênero, sexualidade e educação: uma perspectiva pós-estruturalista. 6. ed. Rio de Janeiro: Vozes, 2003

MACHADO, Aline Gomes; PIRES, Roberto Gondim. Identidade de gênero e suas implicações sobre a sexualidade na perspectiva de professores de Educação Física. Motrivivência, v. 28, n. 48, p. 360$375,2016$.

MADUREIRA, Ana Flávia do Amaral; BRANCO, Ângela Uchoa. Gênero, sexualidade e diversidade na escola a partir da perspectiva de professores/as. Temas em Psicologia, v. 23, n. 3, p. 577-591, 2015.

MENEZES, Moisés Santos; SILVA, Joilson Pereira. Serviço Social e homofobia: a construção de um debate desafiador. Revista Katálysis, v. 20, n. 1, p. 122-129, 2017.

MOTT, L.; CERQUEIRA, M.; MICHELS, E. GRUPO GAY DA BAHIA. Relatório 2017. -População LGBT no Brasil. Disponível em: <https://homofobiamata.files.wordpress.com/2019/01/relatorio-201 7-1.pdf>Acesso em: 07 ago. 2019.

NESELLO, Francine et al. Características da violência escolar no Brasil: revisão sistemática de estudos quantitativos. Revista Brasileira de Saúde Materno Infantil, v. 14, n. 2, 2014.

PARENTE, Jeanderson Soares et al. Álcool, drogas e violência: implicacões para a saúde de minorias sexuais. Reprodução \& Climatério, v. 30, n. 3, p. 108-114, 2015.

SCOTT, Joan. Gênero: uma categoria útil para análise histórica. Texto original: Gender: a useful category of historical analyses. New York, Columbia University Press, 1989. Traduzido por: Christine Rufino Dabat e Maria Betânia Ávila. 


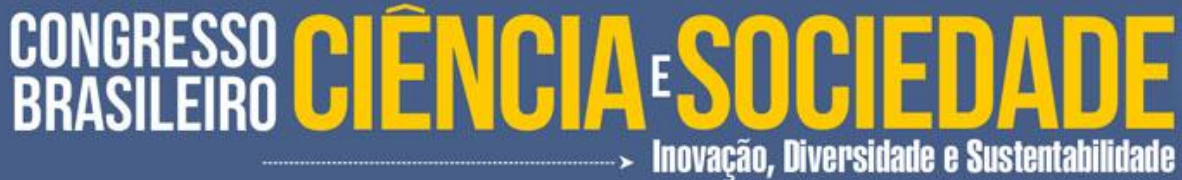

SOUZA, Elaine de Jesus; SILVA, Joilson Pereira da; SANTOS, Claudiene. Representações de docentes acerca da diversidade sexual e homofobia. Revista Estudos Feministas, v. 25, n. 2, p. 519-544, 2017.

SOUZA, Martha Helena Teixeira de et al. Violência e sofrimento social no itinerário de travestis de Santa Maria, Rio Grande do Sul, Brasil. Cadernos de Saúde Pública, v. 31, p. 767-776, 2015.

SOUZA, Marcela Tavares de; SILVA, MICHELLY Dias da; CARVALHO, Rachel de. Revisão integrativa: o que é e como fazer. Einstein (São Paulo), v. 8, n. 1, p. 102-106, 2010.

TOLEDO, Lívia Gonsalves; TEIXEIRA FILHO, Fernando Silva. Homofobia familiar: abrindo o armário 'entre quatro paredes'. Arquivos Brasileiros de Psicologia, Rio de Janeiro, v. 65, n. 3, p. 376-391, 2013.

ZANATTA, Elisangela Argenta et al. Descobrir, aceitar e assumir a homoafetividade: situações de vulnerabilidade entre jovens. Revista de Pesquisa: Cuidado é Fundamental Online, v. 10, n. 2, p. 391-398, 2018.

ZUCCHI, Eliana Miuraet al. Bem-estar psicológico entre travestis e mulheres transexuais no Estado de São Paulo, Brasil. Cadernos de Saúde Pública, v. 35, p. e00064618, 2019.

ALMEIDA, C.B.; VASCONCELLOS, V.A. Transexuais: transpondo barreiras no mercado de trabalho em São Paulo?.Revista Direito GV. v.14, n.2,p.302-333,2018.

VIEIRA, C.; PORTO, R.M. "Fazer emergir o masculino": noções de "terapia" e patologização na hormonização de homens trans. Cad. Pagu.n.55,p.2-32,2019: e195516.

GUIMARÃES, A.N.; MARQUI, G.D.S.; VENDRUSCOLO,C. WERNER, J.M.; ZANATTA, E.A.R. Relatos de jovens homoafetivos sobre sua trajetória e implicações para a saúde mental.Esc Anna Nery.v.23, n.1,p.1-9, 2019:e20180240. 